\title{
2018 Yilında Tek Merkezde Primer Perkutan Koroner Girişim Yapılan Hastaların Klinik Özellikleri, Anjiyografi İşleminin ve Hastane İçi Klinik Sonuçların Analizi
}

Analysis of In-Hospital Clinical Outcomes and Angiography Procedures of Patients Undergoing Primary Percutaneous Coronary Intervention in a Single Center in 2018

Salih Şahinkuş ${ }^{1}$, Muhammed Necati Murat Aksoy ${ }^{1}$, Ercan Aydın², Emre Eynel ${ }^{1}$, Çağla Akçay ${ }^{1}$, İbrahim Kocayiğit ${ }^{1}$, Yusuf Can ${ }^{1}$, Harun Kılıç ${ }^{1}$, Ramazan Akdemir ${ }^{1}$

${ }^{1}$ Sakarya Üniversitesi Eğitim ve Araştırma Hastanesi, SAKARYA

${ }^{2}$ Vakfikebir Devlet Hastanesi, TRABZON

Yazışma Adresi / Correspondence:

Salih Şahinkuş

Güllük Mah. Adnan Menderes Cd. Sağlık Sk. Sakarya Üniversitesi Eğitim ve Araştırma Hastanesi, Adapazarı/Sakarya

T: +905064713599 E-mail : drsalihsahinkus@gmail.com

Geliş Tarihi / Received : 12.12.2019 Kabul Tarihi / Accepted : 01.05.2020

Orcid :

Salih Şahinkuș https://orcid.org/ 0000000315585761

Muhammed Necati Murat Aksoy https://orcid.org/ 0000000277220330

Ercan Aydın https://orcid.org/ 0000000187433762

Emre Eynel https://orcid.org/ 0000000284593418

Çağla Akçay https://orcid.org/0000 00030924 352X

İbrahim Kocayiğit https://orcid.org/0000 000182959837

Yusuf Can https://orcid.org/0000 000245357367

Harun Kılıç https://orcid.org/0000 000213585015

Ramazan Akdemir https://orcid.org/0000 000222623087

( Sakarya Tip Dergisi / Sakarya Med J 2020, 10(2):197-204) DOI: 10.31832 smj.658235

Öz

Amaç Primer perkutan koroner girișim (pPKG), ST elevasyonlu miyokard infarktüsünde (STEMI) ölüm bașta olmak üzere klinik sonuçları fibrinolitik tedaviye kıyasla daha iyi olması üzerine, önerilen ve gittikçe daha yaygın kullanılan tedavi yöntemidir. Amacımız hastanemizde bir yıl içinde yapmış olduğumuz pPKG işlemlerinin ve hastane içi klinik sonuçlarının istatistiksel analizini yapmaktır.

Gereç ve Ocak 2018 ile Aralık 2018 arasında pPKG ile tedavi edilmiş STEMI hastaları retrospektif olarak hastane kayıtlarından belirlendi, anjiyografi görüntüleri izlendi, hastane içi

Yöntem mortalite ve iskemik-kanama-prosedürel komplikasyon oranları analiz edildi.

Bulgular Acil pPKG tedavisi amacıyla kateter laboratuvarına alınmıs olan 982 hasta belirlendi. İslem basarısı oranı \%96.9 idi. Ortalama (Ort) yas kadın hastalarda (69+11)

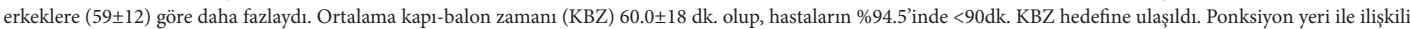
komplikasyon oranına bakıldığında radyal ponksiyon femoral ponksiyona göre daha güvenli bulundu (\%1.4 v.s. \% 3.5, p=0.037). Kardiyojenik șokta olan hastaların mortalite oranı \%76.0'dı. STEMI hastane içi mortalite oranı \%8.6 saptand. Mortal seyreden grupta yaş ort'sı daha yüksekti $(69 \pm 14$ v.s. $60 \pm 12$, p $<0.001)$ ve kadın cinsiyette ölüm oranı (\%15.0 v.s. $\% 6.8, \mathrm{p}<0.001)$ erkeklerdeki ölüm oranına göre anlamlı olarak daha fazla saptandı.

Sonuç Verilerimiz neticesinde, STEMI hastalarında mortalite özellikle kardiyojenik șok tablosundaki hastalar ile, ileri yaș ve kadınlarda daha yüksek saptanmıștır. STEMI hastalarında pPKG kliniğimizde yüksek başarı oranı ile uygulanmaktadır.

Anahtar Primer perkutan koroner girişim; miyokard infarktüsü; koroner arter hastalı̆̆

Öz

Objective Primary percutaneous coronary intervention (PPCI) in the treatment of STEMI is the recommended and increasingly widely used treatment modality, since the clinical outcomes are better than fibrinolytic therapy. The aim of this study is to evaluate of PPCI procedures and in-hospital clinical outcomes in one year period. in-hospital mortality rates were analyzed.

Results 982 patients with STEMI who were admitted to emergency department for PPCI were identified. The success rate of the procedure was $96.9 \%$. The mean age of the patients was higher in female patients ( $69 \pm 11)$ than in men (59 \pm 12$)$. Average door-to-balloon time (DBT) was $60.0 \pm 18$ min. Target DBT $(<90 \mathrm{~min})$ was achieved in $94.5 \%$ of the cases. Radial puncture was found safer than femoral puncture $(1.4 \%$ vs. $3.5 \%, p=0.037)$. Mortality rate of the patients with cardiogenic shock was $76.0 \%$. In-hospital mortality rate of the STEMI patients was $8.6 \%$. Patients who died were older than the survivors $(69 \pm 14$ v.s. $60 \pm 12, p<0.001)$. Mortality rate in females was higher than that in men $(15.0 \%$ v.s. $6.8 \%, p<0.001)$.

Conclusion In conclusion, in patients with STEMI mortality was higher especially in cardiogenic shock, elder age and female sex. pPKG is applied with high success rate to the patients with STEMI in our clinic.

Keywords Primary percutaneous coronary intervention; myocardial infarction; coronary artery disease 


\section{GIIRIŞ}

Tüm dünyada olduğu gibi ülkemizde de en sık görülen ölüm nedeni kardiyovasküler hastalıklardır. Bunun \%60'1 da koroner arter hastalığ (KAH) ile ilişkilidir. ${ }^{1}$ ST elevasyonlu miyokard infarktüsünde (STEMI) akut KAH'in en ölümcül tipi olup, mortalitesi \%20'ye kadar çıkmaktadır. ${ }^{2}$ Acil reperfüzyon tedavisinde dakikaların bile çok önemli olduğu STEMI'da, mortaliteyi ve komplikasyonları azaltması nedeniyle primer perkutan koroner girişim (pPKG) önerilen tedavi stratejisidir. ${ }^{3}$

Çalışmamızda bir yıl içinde, sadece tek merkezde STEMI tanısıyla, pPKG amaciyla kateterizasyon laboratuvarına alınan toplam 982 hastanın klinik özelliklerini, anjiyografik işlemin özelliklerini ve sonuçlarını, hastane içi komplikasyon ve ölüm oranlarını inceledik ve bazı alt gruplarda karşılaştırmalar yaptık. Amacımız pPKG sonuçlarımızın verilerine göre kliniğimiz açısından eksiklerimizin giderilmesi ve literatüre STEMI popülasyonu yoğun olan merkezimizin vaka sayısı ve özellikleri ile katkıda bulunmaktır.

\section{GEREÇ ve YÖNTEM}

Çalışmamız kesitsel tipte tanımlayıcı olarak planlanmış, retrospektif bir çalışmadır. 1 Ocak-31 Aralık 2018 tarihleri arasında Sakarya Üniversitesi Eğitim ve Araştırma Hastanesi kardiyoloji kliniğinde anjiyografi yapılan yaklaşık 6000 hasta arasindan, pPKG amaciyla kateter laboratuvarına alınan 982 hastanın verilerine kateter laboratuvarı ve hastane veri tabanı kayıtlarından ulaşıldı. Çalışmaya dahil edilen tüm hastalar elektrokardiyografide (EKG) ST segment elevasyonu saptanması üzerine acil pPKG amaciyla işleme alınan hastalardı. Hastanemizde 7 gün 24 saat sürekli pPKG hizmeti verilmesi nedeniyle primer fibrinolitik tedavi uygulanan hastamız yoktu. Dış merkezden fibirinolitik tedavi sonrası kurtarıcı PKG amacıyla merkezimize yönlendirilen hastalar dışlama kriteriydi.

Demografik özellikler, hastane içi komplikasyon ve mortalite sonuçlarına hasta dosyalarından ve epikriz bilgilerinden ulaşıldı. Hastanın koroner arterleri ile ilgili verilere kateter laboratuvarındaki kayıtlardan ulaşıldı. İşlem süresi, hastanın anjiyografi masasına yatı̧ıı esnasında yapılan giriş kaydı ile anjiyografide alınan son görüntü kaydı arasindaki zaman olarak belirlendi. Laboratuvar-balon zamanı (LBZ), hastanın pPKG amacıyla kateter laboratuvarına girişi ile STEMI'dan sorumlu lezyonun kılavuz tel ile geçilmesi arasındaki süre olarak değerlendirildi. Kapı-balon zamanı (KBZ) ise, hastanın acil servise başvuru dakikası hastane veri tabanından elde edilerek, bu dakika ile kılavuz telin STEMI'dan sorumlu koroner lezyondan geçmesi arasındaki zaman aralığı olarak belirlendi.

Ejeksiyon fraksiyonu (EF), hastanın pPKG işlemi sonrası koroner yoğun bakımda ilk 24 saat içinde yapılan ekokardiyografisinde, kontrol EF ise taburculuk öncesi yapılan ekokardiyografideki EF değeri olarak tanımlandı. Aritmi, hastanın pPKG işlemine alınmadan önce veya pPKG işlemi esnasında saptanan ventriküler fibrilasyon (VF), ventriküler taşikardi (VT) ve 2.-3. derece atriyoventriküler (AV) bloklar olarak tanımlanmıştır.

Etik kurul onamı alınmıştır, tarih: 02/12/2019, no: 71522473/050.01.04/182. Sakarya Üniversitesi etik kurulu.

\section{İstatiksel Analiz}

Hasta verilerinin istatiksel analizi SPSS 22.0 yazılımı kullanılarak yapıldı. Kategorik değişkenler sayı veya yüzde, sürekli değişkenler ortamala \pm standart sapma olarak ifade edildi. Verilerin normal dağılıma sahip olup olmadığına Kolmogorov-Smirnov testiyle bakılmıştır. Kategorik değişkenlerin karşılaştırılmasında Ki-kare testi kullanıldı. Bağımsız grupların karşılaştırılmasında parametrik Student $t$ test ile yapıldı. 0.05 in altındaki $p$ değerleri istatiksel olarak anlamlı kabul edildi.

\section{BULGULAR}

9 ylldır pPKG tedavisi uygulayan merkezimizde, STEMI nedeni non-obstruktif koroner arterler (MINOKA) olan durumlar ve sorumlu koroner arterdeki anatomik-patolojik nedenlerle invaziv kardiyoloğun acil stentleme tedavisi- 
ni tercih etmemesi gibi nedenler dışlandığında kliniğimizin pPKG başarı oranı \% 96.9 olduğu saptanmıştır.

40 hastada koroner anjiyografide (KAG) aterosklerotik t1kayıcı koroner arter hastalığı saptanmamış olup, EKG'de ST elevasyonuna neden olan durumlar tablo 1'de belirtilmiştir.

\begin{tabular}{|l|c|c|}
\hline $\begin{array}{l}\text { Tablo 1. STEMI tanılı hastalar içinde MINOKA nedenleri ve } \\
\text { sıklığı }\end{array}$ & Sayı & Yüzde \\
\hline Tanı & 16 & $\% 40$ \\
\hline Vazospastik angina & 8 & $\% 20$ \\
\hline Yavaş akım & 4 & $\% 10$ \\
\hline Miyoperikardit & 4 & $\% 10$ \\
\hline Miyokardiyal köprüleşme & 4 & $\% 10$ \\
\hline Ani kardiyak ölüm & 2 & $\% 5$ \\
\hline Koroner çıkış anomalisi & 1 & $\% 2.5$ \\
\hline Erken repolarizasyon & 1 & $\% 2.5$ \\
\hline Non-Kompakt kardiyomyopati & \multicolumn{3}{|c|}{10 Miyok- } \\
\hline $\begin{array}{l}\text { STEMI= ST elevasyonlu miyokard infarktüsü, MINOKA= Mon } \\
\text { ardial infarktion nedeni non-obstruktif koroner arterler }\end{array}$
\end{tabular}

Vasospastik angina tanısı, anjiyografik görüntülemede kritik darlığı olup, intrakoroner olarak uygulanan nitrat tedavisi sonrası yapılan kontrol görüntülemede koroner arter lezyonunun olmadiğ 1 tespit edilerek konulmuştur. Ani kardiyak ölüm (AKÖ) tanılı 4 hasta ise anjiyografik olarak koroner arterlerinde lezyon-diseksiyon-trombüs gibi herhangi bir intrakoroner patoloji saptanmamış, anjiyografik açıdan normal koroner arterleri olan, AKÖ nedeni olarak Akut koroner sendrom (AKS) düşünülmeyen, sonrasında klinik takibinde ekstrakardiyak tanı konulmuş hastalardır.

Yapılan KAG sonucunda pPKG yapılması planlanan 942 hasta saptanmıştır. Hastaların \%78'i erkek, \%22'si kadındır. Yaş ort.'sı erkek hastalarda $59 \pm 12$ yaş ve kadın hastalarda $69 \pm 11$ olarak saptanmıştır. Cinsiyetler arasında yaş ve bazı klinik özgeçmişler istatistiksel olarak anlamlı farklıdır (Tablo 2).
Tablo 2. STEMI tanılı hastalarda cinsiyetlere göre temel klinik özelliklerin karşılaştırılması.

\begin{tabular}{|l|c|c|c|}
\hline Klinik özgeçmiş & $\begin{array}{c}\text { Erkek n=735 } \\
(\% 78)\end{array}$ & $\begin{array}{c}\text { Kadın n=207 } \\
(\% 22)\end{array}$ & P değeri \\
\hline Yaş, ortalama \pm SD & $59 \pm 12$ & $69 \pm 11$ & $<0.001$ \\
\hline $\begin{array}{l}\text { Aktif sigara } \\
\text { içiciliği, n (\%) }\end{array}$ & $477(\% 78.5)$ & $66(\% 31.9)$ & $<0.001$ \\
\hline $\begin{array}{l}\text { Hipertansiyon, } \\
\text { n (\%) }\end{array}$ & $252(\% 34.3)$ & $129(\% 62.3)$ & $<0.001$ \\
\hline $\begin{array}{l}\text { Diyabetes mellitus, } \\
\text { n (\%) }\end{array}$ & $145(\% 19.7)$ & $71(\% 34.3)$ & $<0.001$ \\
\hline Dislipidemi, n (\%) & $90(\% 12.2)$ & $26(\% 12.6)$ & 0.903 \\
\hline $\begin{array}{l}\text { Koroner arter } \\
\text { hastalığı, n (\%) }\end{array}$ & $136(\% 18.5)$ & $33(\% 15.9)$ & 0.396 \\
\hline $\begin{array}{l}\text { Stent öyküsü, n } \\
\text { (\%) }\end{array}$ & $94(\% 12.8)$ & $24(\% 11.6)$ & 0.646 \\
\hline $\begin{array}{l}\text { Koroner by-pass } \\
\text { oyküsü, n (\%) }\end{array}$ & $30(\% 4.1)$ & $6(\% 2.9)$ & 0.433 \\
\hline $\begin{array}{l}\text { İskemik inme, } \\
\text { n (\%) }\end{array}$ & $14(\% 1.9)$ & $6(\% 2.9)$ & 0.381 \\
\hline SD=Standart sapma. & & & \\
\hline
\end{tabular}

\section{Anjiyografik ve prosedürel veriler}

Hastaların acil servise başvuru saatlerine göre gündüz, akşam ve gece olmak üzere üç gruba ayrılmıştır. 08:00-15:59 saatleri arasında başvuran hastalar gündüz, 16:00-23:59 saatleri arasında başvuran hastalar akşam, 00:00-07:59 saatleri arasında başvuran hastalar ise gece başvurmuş olarak kabul edilip kategorize edilmiştir. Klinik özellikleri, komplikasyon oranları ile başvuru saatleri arasında istatistiksel olarak anlamlı fark saptanmamıştır. Ölüm sayısal olarak gece daha sık saptanmış (gece \%11.7, gündüz \%6.4, akşam \%9.8, p = 0.074) ancak istatistiki açıdan anlamlı değere ulaşmamıştır.

Hastaların \%42.2'si anterior MI, \%51.8'i inferior MI, \%2.9'u lateral MI, \%1.7'si posterior MI, \%0.9'u ana koroner/ 3 damar hastalığı ve \%0.6’sı ani kardiyak ölüm tanıları ile işleme alınmıştır.

942 hastanin ortalama syntax skoru $8.0 \pm 3$ olup, syntax skoru <22 olan 917 (\%97.3) hasta ve $\geq 22$ olan 25 (\%2.6) hasta saptanmıștır. 


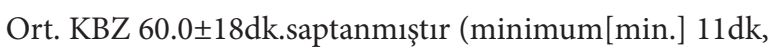
maksimum[maks.]704 dk.). Acil serviste EKG ile STEMI tanısı konulamamış, kardiyolojiye non-STEMI ön tanısiyla troponin takibi yapıldıktan sonra konsulte edilen ve bu nedenle STEMI tanısı ve pPKG işlemi geciken hastalar

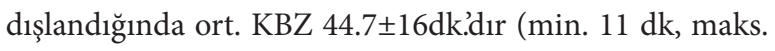
$212 \mathrm{dk}) . \mathrm{KBZ}<60 \mathrm{dk}$. olan hasta sayıs1 691 (\%84.8), 60-90 dk. arasinda 79 (\%9.7), > 90dk olan hasta sayısı 45 (\%5.5) dir. Ort. LBZ 20.0 $\pm 8 \mathrm{dk}$. olup (min.4dk, maks. $86 \mathrm{dk}$.), ort.

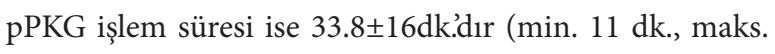
$112 \mathrm{dk}$.$) .$

Trombüs aspirasyonu yapılma oranı \%4.8, non-compliyant (NC) balon ile postdilatasyon yapilma oranı \%9.3, pPKG işlemi esnasında kompleks işlem uygulama oranı \%2.2 olduğu saptanmıştır. NC ile postdilatasyon yapılan hastalarda postdilatasyon yapılmayan hastalara göre, aktif sigara içiciliğinin (\%81.9 v.s. \% 66.9, p=0.002), stent öyküsü olmasının (\%23.9 v.s. $\% 11.4, \mathrm{p}=0.001)$ ve işlem sonrası hastane içi stent trombozu (\%9.1 v.s. $\% 2.8, \mathrm{p}=0.002)$ gelişmesinin daha yüksek oranda olduğu belirlenmiştir. Postdilatasyon yapılan hastalarda stent trombozunun daha sık görülmesi, stent ile istenilen optimal açıklığa ulaşılamayan, daha tromboze, daha kalsifiye daha zor koroner lezyonlarda NC balon ile postdilatasyon uygulanması zorunluluğu açıklanabilir.

$512(\% 54.3)$ hastaya radyal ponksiyon ile, 341 (\%36.1) hastaya femoral ponksiyon ile işlem yapılmış olup, 89 (\%9.4) hastada ise radyal ponksiyonla işleme başlanmış ancak işleme femoral yol ile devam edilmesi gerekmiştir. Femoral ponksiyon ile işlem yapılan hastaların yaş, ko-morbid hastalıklar ile KAH ve CABG öyküsü oranları radyal ponksiyon grubuna göre anlamlı olarak yüksektir (Tablo 3). Yaşı daha ileri, daha çok risk faktörü bulunan hastalarda femoral ponksiyon tercih edildiği için, bu grupta mortalite doğal olarak daha yüksektir. Giriş yeri komplikasyon oranları femoral ponksiyon aleyhine anlamlı olarak farklıdır. Radyal ponksiyon ile yapılan pPKG işlemlerinde ortalama KBZ 8.6 dk. daha fazladır.

\begin{tabular}{|c|c|c|c|}
\hline \multicolumn{4}{|c|}{$\begin{array}{l}\text { Tablo 3. Radyal ve femoral yol ile pPKG yapılan h } \\
\text { klinik özelliklerin ve komplikasyon oranlarının } \\
\text { karşılaştırılması. }\end{array}$} \\
\hline Özellikler & $\begin{array}{c}\text { Radyal } n=512 \\
(\% 60)\end{array}$ & $\begin{array}{c}\text { Femoral } \\
\mathrm{n}=341(\% 40)\end{array}$ & $\mathbf{p}$ \\
\hline Yaş, ortalama \pm SD & $58 \pm 11$ & $65 \pm 13$ & $<0.001$ \\
\hline Erkek, n (\%) & $429(\% 83.8)$ & $242(\% 71)$ & \multirow{2}{*}{$<0.001$} \\
\hline Kadın, n (\%) & $80(\% 16.2)$ & $99(\% 29)$ & \\
\hline $\begin{array}{l}\text { Aktif sigara içiciliği, } \\
\mathrm{n}(\%)\end{array}$ & $396(\% 77.3)$ & $194(\% 56.9)$ & $<0.001$ \\
\hline Hipertansiyon, n (\%) & $171(\% 33.4)$ & $169(\% 49.6)$ & $<0.001$ \\
\hline $\begin{array}{l}\text { Diyabetes mellitus, } \\
\mathrm{n}(\%)\end{array}$ & $104(\% 20.3)$ & $86(\% 26.1)$ & 0.048 \\
\hline Dislipidemi, n (\%) & $41(\% 8.0)$ & $59(\% 17.3)$ & $<0.001$ \\
\hline $\begin{array}{l}\text { Koroner arter hast- } \\
\text { alığı, } \mathrm{n}(\%)\end{array}$ & $67(\% 13.1)$ & $85(\% 24.9)$ & $<0.001$ \\
\hline Stent öyküsü, n (\%) & $56(\% 10.9)$ & $48(\% 14.1)$ & 0.170 \\
\hline $\begin{array}{l}\text { Koroner by-pass } \\
\text { oyküüsü, n (\%) }\end{array}$ & $3(\% 0.6)$ & $32(\% 9.4)$ & $<0.001$ \\
\hline İskemik inme, n (\%) & $8(\% 1.6)$ & $12(\% 3.5)$ & 0.064 \\
\hline $\begin{array}{l}\text { Kapı balon zamanı, } \\
\text { dk (ort. } \pm \text { SD) }\end{array}$ & $61.6 \pm 18$ & $53.0 \pm 15$ & 0.047 \\
\hline Aritmi, n (\%) & $24(\% 4.7)$ & $70(\% 20.5)$ & $<0.001$ \\
\hline $\begin{array}{l}\text { Giriş yeri komp- } \\
\text { likasyonu, n (\%) }\end{array}$ & $7(\% 1.4)$ & $12(\% 3.5)$ & 0.037 \\
\hline $\begin{array}{l}\text { Kontrast madde } \\
\text { nefropatisi, } \mathrm{n}(\%)\end{array}$ & $12(\% 2.3)$ & $7(\% 2.1)$ & 0.778 \\
\hline Ölüm , n (\%) & $14(\% 2.7)$ & $62(\% 18.2)$ & $<0.001$ \\
\hline
\end{tabular}

Hastaların \%68.2'si tek damar , \%23.2'si iki damar, \%8.4'ü çok damar KAH hastasıdır. Çok damar KAH olanlarda ölüm insidansı artmaktadır (tek damar KAH: \%6.4, iki damar KAH: \%11.4, çok damar KAH: \%19.3, p<0.001).

Bir hastaya kardiyojenik şok nedeniyle intraaortik balon pompası takılmıştır. Biri RCA çıkış anomalisi nedeniyle acil pPKG ile revaskülarize edilememesi, biri lezyonun tel ile geçilememesi nedeniyle 2 hastaya anjiyografi sonrası trombolitik tedavi uygulanmış olup, biri sonrasında stent ile biri medikal tedavi edilmiştir. 1 hasta gebe iken STEMI geçirmiştir ve post-MI 4. gün ex olmuştur. 5 tane konjenital koroner çıkış anomalisi, 2 tane konjenital sağ subklavyan arter çıkış anomalisi (arteria lusoria) saptanmıştır. 1 
tane koroner-pulmoner arter fistül saptanmıştır. 5 hastanın aktif malignitesi bulunmaktayd 1 ( 1 akciğer, 1 karaciğer, 1 mesane, 1 testis ve 1 pankreas tümörü). 1 hasta böbrek transplantlı idi. 7 tanesi atriyal fibrilasyon 1 tanesi protez mekanik mitral kapak nedenli olmak üzere 8 hasta coumadin kullanmaktaydı. 9 hastanın bilinen periferik arter hastalığı öyküsü mevcuttu. 1 hastada poliklinikte efor testi esnasında STEMI gelişti ve pPKG ile tedavi edildi. 10 hasta diğer kliniklerde yatmakta iken STEMI teşhisi ile devir alındı ve bunlardan 2 tanesi postoperatif MI tanılıydı. 2'si acil teşhisi konularak, operasyon için kalp damar cerrahisine devredildi.

pPKG işlemi esnasında 799 (\%84.8) hastaya stent işlemi uygulanmıştır. Stent takılmayan 143 hastadan 70 (\%48.9) hastaya sadece balon ile revaskülarizasyon işlemi uygulanmıştır. Stent takılmamasının başlıca nedenleri; sorumlu koroner arterin ince-tortioz-kalsifik olması, yoğun trombüs nedeniyle balon ile pPKG uygulanıp, antiagregan-antikoagülan infüzyonu sonrası kontrol KAG önerilmesi, eski stent trombozuna balon ile pPKG yapılması ve cerrahi koroner revaskülarizasyon önerilmesi gibi durumlardır.

\section{Komplikasyonlar}

Yapılan pPKG işlemi sonucu 25 (\%2.6) hastada hastane içi stent trombozu (ST) gelişmiştir. Bunların 13'ü (\%52) akut olup beş hastaya tekrar stentleme yapılmıştır, 12'si(\%48) subakut ST olup, 8 hastaya tekrar stent implante edilmiştir. Tüm ST vakalarımıza GpIIb/IIIa antagonisti infüzyonu verilmiştir. Genel olarak 942 hastada pPKG işlemi sonrası GpIIb/IIIa antagonisti infüzyonu kullanılma oranı ise \%6.9'dur.

Başarılı revaskularizasyon uygulanana dek, işleme alınmadan önce veya işlem esnasında kateter laboratuvarında aritmi insidansı \%10.8 (102 hasta) olup; 59 VF, 6 VT, 36 AV tam blok ve 1 Mobitz tip 2 blok görüldüğü belirtilmiştir. AV tam blok ile başvuran hastaların \%72.2'sine geçici pacemaker implante edilmiştir.
Hastane içi görülen MI komplikasyonu, 75 kardiyojenik şok, 1 iskemik mitral yetersizliği, 1 apikal trombüs, 1 ventriküler anevrizma ve 2 post-MI perikardit olmak üzere 80 (\%8.1) vaka saptanmıştır. Post-MI, 3 tanesi birinci gün, 1 tanesi ikinci gün ve 1 tanesi dördüncü günde olmak üzere toplam 5 hastada iskemik inme gelişmiştir. İşlem ile ilgili komplikasyon olarak, 3 radyal oklüzyon, 1 sağ boyun hematomu, 3'ü kolda, 8'i kasıkta olmak üzere toplam 11 tane ponksiyon yerinde anlamlı hematom, 1 femoral A-V fistül, 2 psödoanevrizma, 1 tane sonrasinda greft stent ile perkutan olarak tedavi edilen sağ ilyak arter rüptürü, 1 tane RCA'da stent sırrılması olmak üzere toplam 20 (\%2.1) hastada komplikasyon gelişmiştir. Toplam 19 (\%2.0) hastada kanama görülmüş olup 15’i giriş yeri ile ilişkili, 4 tanesi ise üst gastrointestinal sistem kanamasıdır.

27 (\%2.74) hastada kontrast madde ilişkili nefropati (CIN) gelişmiş olup, 22'si medikal tedavi ile düzelmiş, 5’i hemodiyalize alınmış ve bunlardan bir tanesinin hemodiyaliz tedavisi kronik hale gelmiş, hasta post-MI 3. ayda ex olmuştur. CIN gelişen hastaların yaş ortalaması daha yüksek (68.0 v.s. 61.1, p=0.002), EF’si daha düşük (\%37 v.s. \%44, $\mathrm{p}=0.01)$ ve no-reflow komplikasyonu gelişen hastalarda (\%11.1 v.s. \%2.3, p=0.004) daha sık CIN geliştiği görülmüştür. CIN gelişen hastalarda hastane içi mortalite görülmemiştir.

STEMI tanısı ile kateter laboratuvarına alınmış toplam 982 hastanın verilerinin analizinde, 12 hasta kateter laboratuvarında işlem esnasında (9'u pPKG işlemine başlanamadan), ilk gün 33, 2. gün 21 hasta olmak üzere, hastane içi mortalite oranı \%8.6 saptanmıştır. Ölüm ile ilişkili istatistikler tablo 4'de gösterilmiştir. Mortalitenin olduğu grupta sigara içiciliği daha az oranda görülmesinin nedeni; sadece aktif sigara içenlerin bu gruba dahil edilmesidir, daha öncesinde sigara kullanıp bırakmış olan hastalar aktif sigara içmiyor grubuna dahil edilmiştir. Mortalite grubundaki 85 hastadan 57'si gelişinde kardiyojenik şoktaydı. Kardiyojenik şokta başvuran toplam 75 (\%7.9) hasta vardı ve kardiyojenik şok ile başvurma sonucu mortalite \%76.0 olarak 
saptandı. Yatışı süresince entübe olmuş 106 (\%11.2) hasta vardı ve entube hastaların mortalitesi \% 28.3 idi.

\begin{tabular}{|c|c|c|c|}
\hline & $\begin{array}{c}\text { Ölüm (+) } \\
\mathrm{n}=85(\% 8.6)\end{array}$ & $\begin{array}{c}\text { Ölüm (-) } \\
\mathrm{n}=897 \\
(\% 91.3)\end{array}$ & $\mathrm{p}$ \\
\hline Yaş, ortalama $\pm S D$ & $69 \pm 14$ & $60 \pm 12$ & $<0.001$ \\
\hline Erkek, n (\%) & $52(\% 6.8)$ & $242(\% 71)$ & \multirow{2}{*}{$<0.001$} \\
\hline Kadın, n (\%) & $33(\% 15.0)$ & $710(\% 93.1)$ & \\
\hline $\begin{array}{l}\text { Aktif sigara içenler, } \\
\mathrm{n}(\%)\end{array}$ & $37(\% 44.6)$ & $606(\% 70.5)$ & $<0.001$ \\
\hline Hipertansiyon, n (\%) & $45(\% 54.2)$ & $336(\% 39.1)$ & 0.007 \\
\hline $\begin{array}{l}\text { Diyabetes mellitus, } \\
\mathrm{n}(\%)\end{array}$ & $20(\% 24.1)$ & $196(\% 22.8)$ & 0.791 \\
\hline Dislipidemi, n (\%) & $16(\% 19.3)$ & $100(\% 11.6)$ & 0.043 \\
\hline $\begin{array}{l}\text { Koroner arter hast- } \\
\text { alığı, } \mathrm{n}(\%)\end{array}$ & $23(\% 27.7)$ & $146(\% 17.0)$ & 0.015 \\
\hline İskemik inme, n (\%) & $6(\% 7.2)$ & $14(\% 1.6)$ & 0.001 \\
\hline Anterior MI, n (\%) & $37(\% 9.3)$ & $412(\% 90.7)$ & \multirow{2}{*}{0.488} \\
\hline İnferior MI, n (\%) & $39(\% 8.0)$ & $447(\% 92.0)$ & \\
\hline $\begin{array}{l}\text { Kapı balon zamanı, } \\
\text { dk. (ort. } \pm S D)\end{array}$ & $69 \pm 70$ & $59 \pm 66$ & 0.209 \\
\hline $\begin{array}{l}\text { Masa balon zamanı, } \\
\text { dk. (ort. } \pm \text { SD) }\end{array}$ & $20 \pm 13$ & $20 \pm 10$ & 0.520 \\
\hline $\begin{array}{l}\text { İșlem süresi, dk. } \\
\text { (ort. } \pm \text { SD) }\end{array}$ & $38 \pm 22$ & $33 \pm 16$ & 0.020 \\
\hline $\begin{array}{l}\text { Spontan rekanalize, } \\
\mathrm{n}(\%)\end{array}$ & $14(\% 16.9)$ & $205(\% 23.6)$ & 0.150 \\
\hline No-reflow, n (\%) & $4(\% 4.8)$ & $20(\% 2.3)$ & 0.169 \\
\hline $\begin{array}{l}\text { Stent trombozu, } \\
\mathrm{n}(\%)\end{array}$ & $3(\% 3.6)$ & $29(\% 3.4)$ & 0.910 \\
\hline $\begin{array}{l}\text { Ejeksiyon fraksi- } \\
\text { yonu, \% ort } \pm \text { SD }\end{array}$ & $32.0 \pm 9$ & $45.1 \pm 11$ & $<0.001$ \\
\hline $\begin{array}{l}\text { Kardiyak arrest, } \mathrm{n} \\
(\%)\end{array}$ & 77 (\% 92.8) & $23(\% 2.7)$ & $<0.001$ \\
\hline \multicolumn{4}{|c|}{ MI= Miyokard İnfarktüsü, $S \mathrm{D}=$ Standart sapma. } \\
\hline
\end{tabular}

\section{TARTIŞMA}

STEMI tanısı ile acil KAG yaptığımız 982 hastayı kapsayan çalışmamızda hastane içi mortalite oranı \%8.6 saptandı. Bu oran daha önce yayınlanmış çalışmaların mortalite oranlarına (\%5.9-\%14.8) benzerdi. ${ }^{4,5}$ STEMI'nda mortaliteyi oldukça artırdığı bilinen kardiyojenik şok komplikasyonun, bizim sonuçlarımızda da mortalitesi (\%76.0) literatür ile benzer oranda yüksekti. ${ }^{6}$ Ort. LBZ $20.0 \pm 8$ dk. olup, KBZ $\leq$ $90 \mathrm{dk}$. işlem oranımız ise \%94.5'tir. İlimizde 7 gün 24 saat acil pPKG uygulayan tek merkez olmamıza rağmen, acil servis hekimi tarafından EKG ile STEMI tanısı konulamamış, troponin takibi ile zaman kaybedilen hastalar dışlandığında, doğrudan STEMI tanısı konularak pPKG uygulanan hastalarda ort. KBZ $44.7 \pm 16 \mathrm{dk}$. olup, literatürdeki verilerle karşılaştırıldığında merkezimizin KBZ’nin iyi olduğunu söyleyebiliriz. ${ }^{7}$ KBZ, STEMI hastalarında morbidite ve mortalite ile ilişkilidir. ${ }^{8}$ Hastaneye başvuru ile kateter laboratuvarının hazırlanması arasındaki sürenin $\leq 20 \mathrm{dk}$. olmasının, hedeflenen KBZ ( $\leq 90 \mathrm{dk}$.) için anahtar olduğu belirtilmiştir. ${ }^{9}$

Genel STEMI popülasyonumuz içinde MINOKA oranı \% 4.0 olup, hastane içi mortalite bu hastalarda \% 2.5’tir. 16849 MINOKA tanılı hastanın 1 yıllık takibinde mortalite oranı $\% 12.3$ saptanmıştır. ${ }^{10}$ Verilerimizdeki etyolojiye baktığımızda \%75 koroner, \% 15 non-koroner kardiyak ve $\% 10$ hastada ekstrakardiyak etkenler olduğunu görmekteyiz. Gue ve ark. 110 MINOKA hastasının etyolojisinde \%28 koroner, \% 61 non-koroner kardiyak nedenler olduğunu saptamış, non-koroner etkenler miyokardit, Takotsubo sendromu ve tip-2 MIdan oluşmuştur. ${ }^{11}$

Cinsiyetler arasındaki farklılıklara baktığımızda, kadın hastaların yaş ort.sının daha yüksek, HT ve DM gibi ko-morbid hastalık prevelansı daha yüksek, anterior lokasyona kıyasla inferior MI tanısı daha sık, femoral ponksiyon kullanımı daha sık ve kadınlarda mortalite oranının erkek hastalara kıyasla daha fazla olduğunu saptadık. Kadınlarda anterior MI sıklığının daha az olduğu daha öncede belirtilmiştir. ${ }^{12} 2$ yıllık takipte STEMI hastalarında erkeklere kıyasla kadınlarda mortalitenin daha yüksek olduğu gösterilmiş ( $\mathrm{p}=0.0009)$ ancak, çok değişkenli istatistiksel analizde kadın cinsiyetin hastane içi ve uzun dönem mortalite için prediktif olmadığ 1 gösterilmiştir. ${ }^{13}$ Kanic ve ark. tarafından, STEMI hastalarında 30 günlük ve uzun dönem düzeltilmemiş mortalite oranının kadınlarda daha yüksek olduğu saptanmış ve yine kadınlarda yaş, ko-mor- 
bid hastalıklar, anemi ve böbrek yetmezliği oranının daha yüksek olduğu gösterilmiş. Bunun üzerine yapılan düzeltilmiş çok değişkenli istatistiksel çalışma sonucunda erkek kadın cinsiyetler arasında 30 günlük mortalite oranında anlamlı farklılık olmadığı, uzun dönem mortalite oranının ise kadınlarda daha düşük olduğu saptanmıştır. ${ }^{14}$

Ponksiyon yerine göre karşılaştırma yaptığımızda, ort. KBZ radyal ponksiyon grubunda daha uzun, giriş yeri komplikasyon oranları daha önce yayınlanan çalışmaların sonuçlarına benzer durumda femoral ponksiyon hastalarında daha yüksektir. ${ }^{15}$ Femoral ponksiyon yapılan hastalarda aritmi ve ölüm oranının oldukça yüksek olduğu görülmektedir ancak, bu hastalarda ortalama yaş, ko-morbid hastalıklar, KAH ve CABG öyküsü oranlarının radyal ponksiyon yapılan hastalara göre daha yüksek olduğunu, bu iki grubun randomize olmadığını değerlendirmek gerekir.

Verilerimize göre pPKG uyguladığımız hastalarda daha önce yayınlanan çalışmaların sonuçlarına benzer oranda CIN gelişmiş olmakla birlikte, erken tanı ve tedavi sayesinde CIN gelişen 27 hastamızda hastane içi mortalite görülmemiştir. ${ }^{16}$

MINOKA haricindeki 942 hastanın \%84.8'i stent ile, \%7.4'ü primer balon anjiyoplasti ile tedavi edilirken, \%7.7'sine ise medikal veya cerrahi tedavi önerisi ya da işlem başarısızlığı nedeniyle pPKG yapılmamıştır. Stent implantasyonu kliniğimizde standart pPKG tedavi yöntemi olmakla birlikte, bazı hastalarda stent implante edilmemesi bir tercih değil, hastanın koroner arter lezyonu karakteristiği itibariyle bir zorunluluk olmuştur. Stent ile pPKG tedavisi uygulanan hastalar ile karşılaştırıldığında, stent implante edilmeyen hastaların mortalitesi (\%22.4v.s. $\% 6.4, \mathrm{p}=0.001$ ) daha yüksektir. Bu iki grubun randomize olmadığını, stent implante edilmeden tedavi edilen hastaların daha yaşlı ve daha çok ko-morbiditesi olduğunu da göz önünde bulundurmak gerekir. Yıllar önce yayınlanan Stent Primary Angioplasty in Myocardial Infarction
(STENT PAMI) ve Controlled Abciximaband Device Investigation to Lower Late Angioplasty (CADILLAC) çalışmalarında, stent ile pPKG’nin balon ile tedaviye kıyasla mortalite, inme ve reinfarkt oranlarını azaltmadığı ancak, restenoz ve revaskülarizasyon oranlarını azaltığı gösterilmiştir. ${ }^{17}$ Günümüzde pPKG esnasında stent ve balon ile tedaviyi karşılaştıracak yeni bir çalışma yapmak çok olası değildir. Yeni jenerasyon ilaç kaplı stentler ve yeni antiplatelet ajanların kullanımının yaygınlaşması ile stent trombozu, restenozu ve reinfarkt oranlarının azaldığını klinik olarak gözlemlemekteyiz.

Sonuç olarak, uzun zamandır STEMI tedavisinde pPKG uygulayan merkezimizde işlem başarı oranı yüksek, komplikasyon ve mortalite oranlarının ise literatür ile benzer oranlarda olduğunu görmekteyiz. Kadınların daha ileri yaşta olduğu ve buna bağlı olarak kadınların daha fazla ko-morbid hastalık eşliğinde STEMI teşhisi aldığını ve sonuç olarak kadınlarda STEMI hastane içi mortalitesinin daha yüksek olduğunu görmekteyiz. KBZ ortalama süresinin iyi olmasına ve pPKG işlem başarısının yüksek olmasına rağmen halen kardiyojenik şok oldukça mortal seyreden bir klinik tablodur.

Etik kurul onamı alınmıştır, tarih: 02/12/2019, no: 71522473/050.01.04/182. Sakarya Üniversitesi etik kurulu. 
Sakarya Tip Dergisi 2020;10(2):197-204

ŞAHINKUȘ ve Ark., Primer Perkutan Koroner Girişim Verilerinin Analizi

\section{Kaynaklar}

1. Gümrükçüoğlu HA, Șahin M, Eryoncu B, et al. Kliniğimizde kardiyak kateterizasyon uygulanan hastalıkların üç ylllık sonuçlarının istatistiksel analizi. Van Tip Dergisi 2006;13(3): 78-84.

2. Dubey G, Verma SK, Bahl VK. Primary percutaneous coronary intervention for acute $S T$ elevation myocardial infarction: Outcomes and determinants of outcomes: A tertiary care center study from North India. Indian Heart Journal 2017;69:294-98.

3. Ibanez B, James S, Agewall S, et al. 2017 ESC Guidelines for the management of acute myocardial infarction in patients presenting with ST-segment elevation. European Heart Journal (2018) 39:119-177.

4. Temiz A, Gazi E, Güngör Ö, et al. Platelet/lymphocyte ratio and risk of in-hospital mortality in patients with ST-elevated myocardial infarction. Med Sci Monit 2014 (22);20:660-5.

5. Ugalde H, Yubini MC, Rozas S, et al. Prediction of hospital mortality of ST elevation myocardial infarction using TIMI score. Rev Med Chil 2017;145(5):572-578.

6. Shaikh AH, Siddiqui MS, Hanif B, et al. Outcomes of primary percutaneous coronary intervention in a tertiary care cardiac centre. J Pak Med Assoc 2009;59:426-29.

7. Yekefellah L, Pournorooz M, Noori $H$, et al. Evaluation of door-to-balloon time for performing primary percutaneous coronary intervention in ST-segment elevation myocardial infarction patients transferred by pre-hospital emergency system in Tehran. Iran J Nurs Midwifery Res 2019;24(4):281-5.

8. Nallamothu BK, Bradley EH, Krumholz HM. Time to treatment in primary percutaneous coronary intervention. N Eng J Med 2007;357:1631-8.

9. McCabe JM, Armstrong EJ, Hoffmayer KS, et al. Impact of door-to-activation time on door-to-balloon time in primary percutaneous coronary intervention for ST-segment elevation myocardial infarctions. Cardiovasc Qual Outcomes 2012;5:672-9.

10. Dreyer RP, Tavella R, Curtis JP, et al. Myocardial infarction with non-obstructive coronary arteries as compared with myocardial infarction and obstructive coronary disease: outcomes in a medicare population. Eur Heart J e-pub2019 Jun 21. pii: ehz393. doi: 10.1093/ eurheartj/ehz403.
11. Gue YX, Corballis N, Ryding A, et al. MINOCA presenting with STEMI: incidence, aetiology and outcome in a contemporaneous cohort. Journal of Thrombosis and Thrombolysis 2019 Nov; 48(4):533-538.

12. Maznyczka AM, Carrick D, Carberry J, et al. Sex-based associations with microvascular injury and outcomes after ST-segment elevation myocardial infarction. Open Heart 2019 Apr 29;6(1):e000979. doi: 10.1136/openhrt-2018-000979. eCollection 2019.

13. Zachura $M$, Wilczek $K$, Janion $M$, et al. Long-term outcomes in men and women with ST-segment elevation myocardial infarciton and incomplete reperfusion after a primary percutaneous coronary intervention: a 2-year follow-up. Coronary Artery Disease 2019;30: 171-6.

14. Kanic V, Suran D, Krajnc I, et al. ST-elevation myocardial infarction in a real population-An observational retrospective study with a sexperspective. Eur J InternMed. 2019;66:81-84.

15. Schernthaner $C$, Hammerer $M$, Harb S, et al. Radial versus femoral access site for percutaneous coronary intervention in patients suffering acute myocardial infarction. Wien Klin Wochenschr 2018;130:182-9.

16. Dubey L, Bhattacharya R, Guruprasad S, et al. Early clinical outcomes of primary percutaneous coronary intervention in Bharatpur, Nepal. A Journal of Clinical Medicine 2013;8(2):103-7.

17. Kalra S, Bhatt H, Kirtane AJ. Stenting in primary percutaneous coronary intervention for acute ST-segment elevation myocardial infarction. Methodist Debakey Cardiovasc J 2018; 14(1):14-22. 